\title{
An Applied Study on Using Laser for the Conservation of an Archaeological Textile Embroidered with Metal Threads at the Museum of the Faculty of Applied Arts, Helwan University (No. 121/5)
}

\author{
Neama A. Shehata1, Mohamed A. Marouf², Badawy M. Ismail ${ }^{3}$ \\ ${ }^{1}$ Ministry of State for the Antiquities Affairs, Cairo, Egypt \\ ${ }^{2}$ Conservation Department, Faculty of Archaeology, Sohag University, Sohag, Egypt \\ ${ }^{3}$ Conservation Department, Faculty of Archaeology, Luxor University, Luxor, Egypt \\ Email: neama.adelazeem@yahoo.com, neamaabdelazeem@gmail.com
}

How to cite this paper: Shehata, N. A., Marouf, M. A., \& Ismail, B. M. (2020). An Applied Study on Using Laser for the Conservation of an Archaeological Textile Embroidered with Metal Threads at the Museum of the Faculty of Applied Arts, Helwan University (No. 121/5). Archaeological Discovery, $8,117-134$.

https://doi.org/10.4236/ad.2020.82007

Received: December 19, 2019

Accepted: February 28, 2020

Published: March 2, 2020

Copyright $\odot 2020$ by author(s) and Scientific Research Publishing Inc. This work is licensed under the Creative Commons Attribution-NonCommercial International License (CC BY-NC 4.0). http://creativecommons.org/licenses/by-nc/4.0/ (c) (7) \&) Open Access

\begin{abstract}
There is an urgent need to use laser cleaning for a complicated textile because it is an effective technique for metal artifacts. It offers a high degree of control, especially in cleaning fragile and very detailed artifacts (Abdel-Kareem \& Al-Saad, 2007). The inherent unique properties of laser light, such as intensity, monochromaticity, directionality, and coherence, have made lasers effective tools in a variety of applications in the industrial and biomedical fields. Furthermore, a good understanding of the phenomena happening at the interaction of laser radiation with materials is fundamental for the success and optimization of any laser-based application. Therefore, laser cleaning depends on the nature of the material to be removed (Fotakis, Anglos, Zafiropulos, Georgiou, \& Tornari, 2007). The study adopted Q-switched Nd:YAG laser, which is the most common type in conservation. It employed investigation and analysis devices, such as SEM-EDX, XRF, and XRD.
\end{abstract}

\section{Keywords}

Laser, Archaeological Textile, Metal Threads, Deterioration, Sewing Support

\section{Introduction}

Precious metals have been used for the decoration of textiles since ancient times to create luxury objects for the secular and religious elite. Metal threads have 
been interwoven into fabrics, used decoratively in tapestry and embroidery. They are traditionally associated with the use of silk. They are considered luxury materials engaged in the manufacture of the finest and most expensive fabrics (Karatzani, 2012). Embroidery cloths were one of the finest textile products in the $16^{\text {th }}$ century in Europe (Cybulska, 2015).

Metal threads are primarily copper, zinc, silver, or gold plated. Because they were made of precious metals and organic fibers, embroidered clothing was a sign of wealth and social status. There are many types of metal threads, including metal strips, wires, strip wound around a silk yarn (are shown in Figure 1). The thickness of the precious metal is some micron. The substrate of embroidered items is often cotton, flax, hemp, wool, or mixed-colored materials (Radojkouić, Ristic, Zrilić, \& Suzana, 2015). Furthermore, gold threads were used in embroidery and made in different ways (Járó, 1990). The metals used in making metal threads were predominantly gold, silver, copper, and zinc, as a component of copper alloys (Timar-Balazsy \& Esto, 1998).

\subsection{Archaeological Description of the Textile}

\subsubsection{Archaeological Description from the Museum Records}

The sample covered three square Italian-style cloth embroidered with gold and light brown threads on a red background decorated with floral and bird-like decorations. They are $260 \mathrm{gm}$ and measure $(86 \mathrm{~cm} \times 86 \mathrm{~cm})$. The textile is a double-layer embroidered with metal threads with many beige decorations on a background of red silk. The basic decorative element is a bird (butterfly) and dominated by different floral motifs (see Table 1).

\subsubsection{Artistic Description of the Archaeological Textile}

The monument is a piece of a squared red silk textile decorated with flying birds. The external frame and above the flying wings of the birds are beige, suggesting dense feathers. The birds are light beige, but the head is not clear enough. Furthermore, the background is decorated with floral motifs in the form of curled plant branches like semi-circles. Some branches have brown leaves surrounded by three-leaf and four-leaf light beige flowers in some parts. These brown branches dominate the four corners. In addition, some leaves are near the tail of the bird in the form of dense down-up branches that come out of a hidden stem because of the abundant (dark) brown leaves (are shown in Figure 2). The brightness of the brown color disappeared due to accumulations of aerosols, especially in the leaves.

There are many floral paintings in the form of a dark brown stem on a dark white background. The stem was somewhat shining before cleaning. In the lower part of the stem, there is a single leaf topped, from the other side, by three flat leaves with a dotted white corona reflecting them on a red background. It is topped by two leaves out of the stem. A part of the lower leaf is covered by the upper one. On the left, there is a bigger leaf linked with the head of the bird. The stem ends with two emerging small stems with three leaves each. The main stem is topped by a set of single or overlapping leaves like the end. The leaves are encircled by a shadow or a dotted white corona showing the leaves properly. 

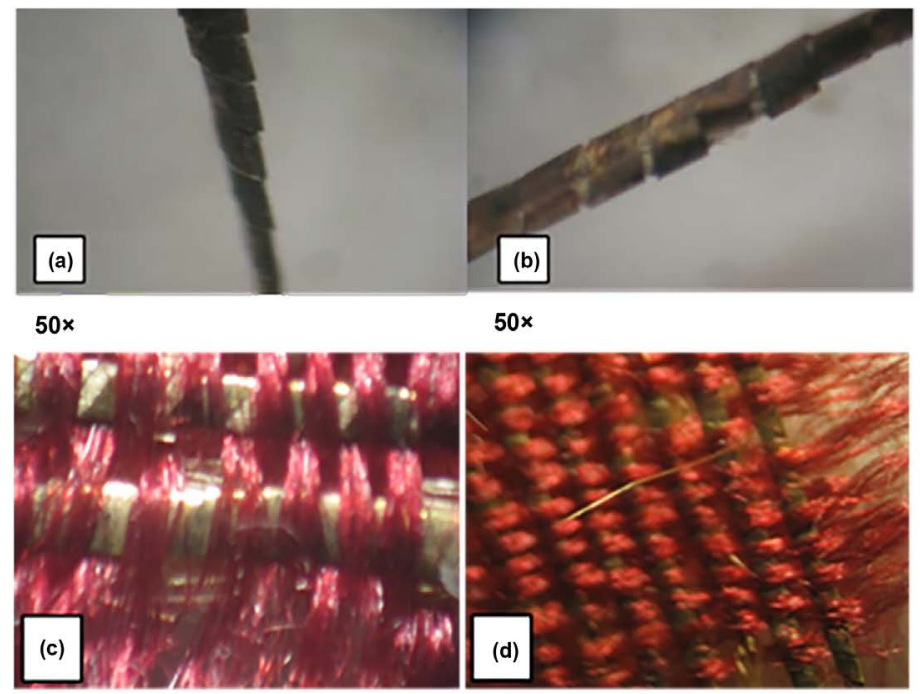

$50 x$
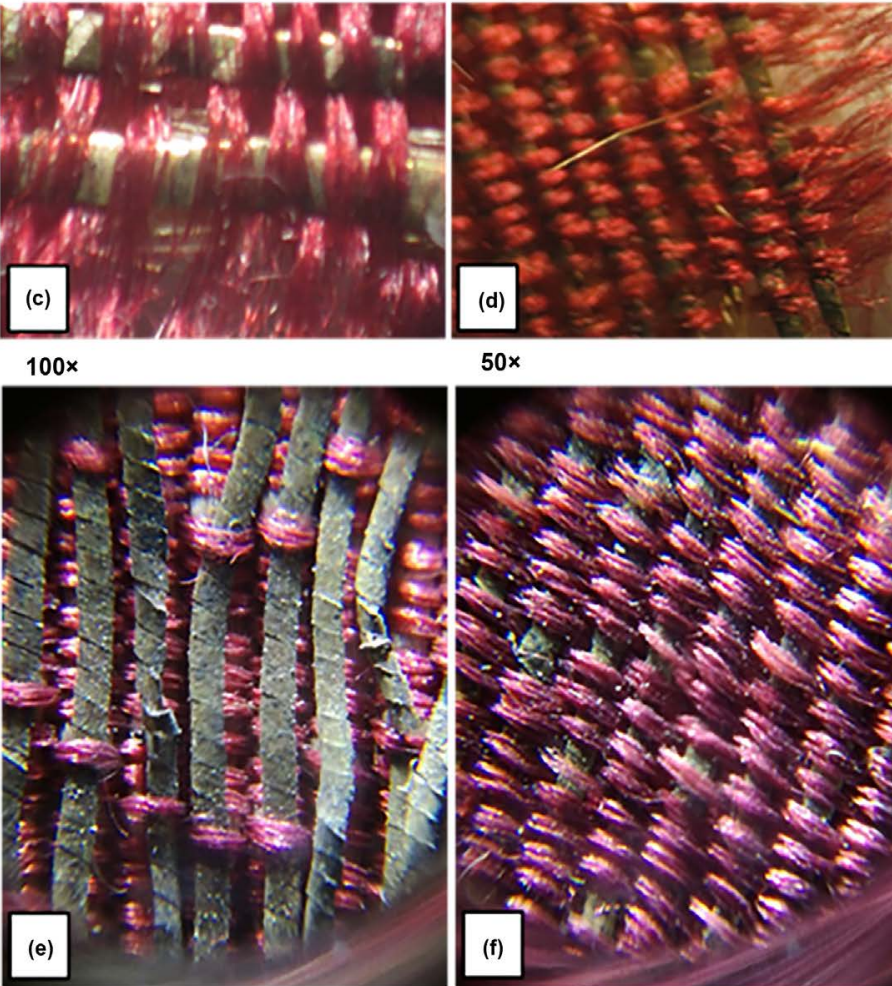

$50 x$

$50 x$

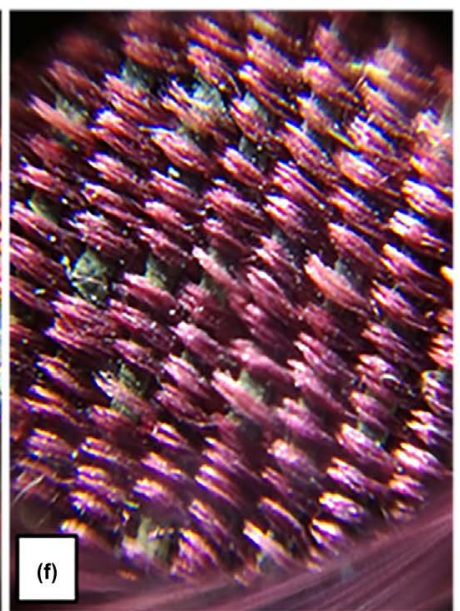

$50 \times$

Figure 1. Stereo Microscope shows archaeological metal threads and direction (S) and the texture structure of the archaeological textile.

Table 1. Technical specifications of the archaeological textile.

\begin{tabular}{cc}
\hline Specification & Description \\
\hline Measurement & $90 \mathrm{~cm} \times 85 \mathrm{~cm}$ \\
Warp density & 1 yarns \\
Weft density & 46 yarns \\
Weave structure & Atlas \\
Yarn twist direction & The direction of the warp and weft is S \\
Fibers & Silk fibers embroidered with copper threads \\
Colors & Red and embroidered with beige copper threads \\
Ornaments & Flying birds and floral motifs \\
Place of preservation & Museum of the Faculty of Applied Arts \\
Save number & (No. 121/5) \\
\hline
\end{tabular}




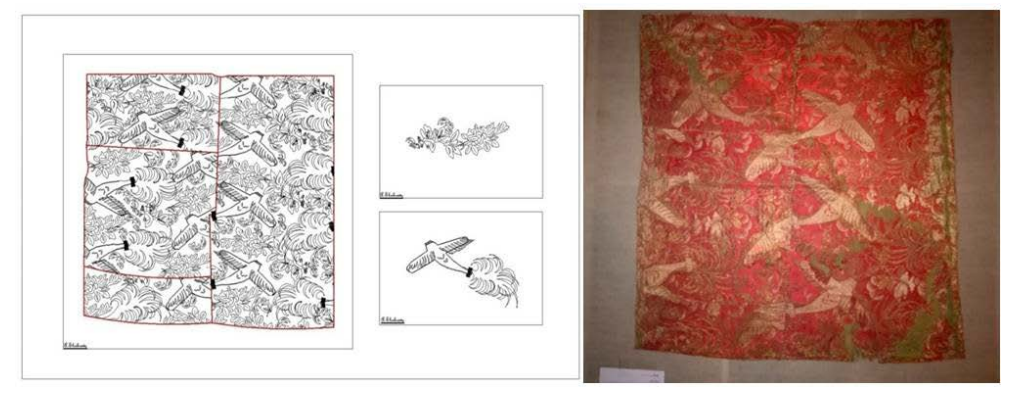

Figure 2. The archaeological textile, decoration figures on the archaeological textile.

These signs suggest the artists' link with the nature and ability to create a special one as shown in the art and depictions on this textile. When considering these light brown birds on a red background, two dimensions appear, even if the artist tried to integrate a simple part of the third dimension of the wings by highlighting the feather, taking an inclination in line with the flying wings. The artist did not adopt the three dimensions completely in depiction and modified the basic shape of birds. However, this did not show a lack of skills. Rather, it is a philosophy.

Since ancient times, the philosophy of modified art has appeared. It was clear in the era of Akhenaten of the New Kingdom when colossal sculptures, wall paintings, and papyri differed from the stereotyped nature of the masculine body that had feminine qualities. In implementing the artworks of Akhenaten, the artist always adopted certain ways to create an intersex form.

Furthermore, modified artifacts appeared in Coptic art, especially in the early period. The Coptic artist modified artworks significantly, which affected the Coptic textiles, especially tapestry. For example, the paintings were modified to be semi-human, semi-animal, and semi-bird. This was not because of the poor skills, but the Coptic artist who inherited the great Ancient Egyptian civilization had a religious and artistic philosophy. It might be due to the artistic features of the time.

In the early Islamic era, the modification of artworks was significant for religious purposes because painting and sculpture of the people and the animals were prohibited or undesirable. Therefore, the Muslim artist did not depict nature. Instead, he modified it greatly or adopted floral motifs and Arabic scripts.

If he used human and animal depictions, he made significant modifications to the dimensions. Thus, he benefited from the Sasanian and Ancient Near Eastern arts that were ruled by the Muslims. The artists in these areas modified their artworks based on imagination in deducing the shapes of animals or combining animals and birds. In the present artifact, the artist made substantial modifications to the birds.

He implemented them using a needle accurately, illustrating significant skill in implementation using metal threads. The selections of colors were successful. For example, the vivid red background attracts attention. Once seen, the artifact seems to be a unique colorful figure with its vivid and attractive red color. It shows a whole life with the reflections of the rainbow. 
This integrated life comprises floral nature with leaflets of different lengths hanging down suggesting stability and environmental cohabitation. Their dark color within the brilliant red background. These leaves may belong to wild plants, suggesting harmony between the environment and the plants. In other words, they grow naturally and comfortably to highlight the artistic stability of the painting items.

The textile was implemented in a creative manner artistically. In terms of color selection and dimension, many eastern artistic traditions united, including accuracy, floral motifs, modified birds to mirror the spirit of the nature-loving artist. For example, birds were modified with unique flying wings to enrich the textile.

The tails had slight bowing, affirming the birds' stable movement. The coherent and stable movement of the wings and tails suggest that the birds are aware of their objectives. Furthermore, the birds' direction indicates the unity of objectives. Their coherent and stable movement suggests complete understanding in these places and familiarity with their positions.

Although the dimensions of birds are not atypical in terms of embodiment because of modifications and being $2 \mathrm{D}$ only, the dimensions between the body, tail, wing, and head were modified by the artist and differed completely from nature. The artist could create an amazing picture of the embodied birds moving towards a certain objective.

Studying the stand of the textile illustrates that it is made of hard white wood and measures $120 \mathrm{~cm} \times 120 \mathrm{~cm}$, but the textile measures $85 \mathrm{~cm} \times 90 \mathrm{~cm}$. The textile is fixed on a linen cloth on a wooden stand with external square wooden corners with a periphery of $4 \mathrm{~cm} \times 4 \mathrm{~cm} \times 4 \mathrm{~m} \times 4 \mathrm{~cm}$. Additionally, the wooden corners were supported in the middle with two white wooden planks with a periphery of $2.5 \mathrm{~cm} \times 3.5 \mathrm{~cm} \times 2.5 \mathrm{~cm} \times 3.5 \mathrm{~cm}$ to support the surrounding blanks containing the cloth holding the textile. The first blank is about $37 \mathrm{~cm}$ to the right of the external frame, while the second one is $36 \mathrm{~cm}$ to the left of the external frame. The frame is cross-fixed in the middle with a wooden blank that measures $2.5 \mathrm{~cm} \times 3.5 \mathrm{~cm} \times 2.5 \mathrm{~cm} \times 3.5 \mathrm{~cm}$ in order not to bend over the archaeological textile (see Figure 3).

The archaeological textile is fixed from the corners in the middle area of the linen cloth using magic stitches of a mean thick red silk yarn. It contains metal threads on a pale green background appearing from some lost parts. In the right low part, a large area and some small areas of the metal threads used to implement the paintings are lost. However, the background is almost complete, but with accumulated dirt and dust affecting the main color and turning it pale. Therefore, the green color is light and covered with much dust and dirt caused by air pollutants.

Many metal threads appear single and stretching down-up due to the loss of many metal threads connected with them. Some threads are slope, and others appear in the parts of the archaeological textile as they are disconnected from the others that lost integrity on the background. They are soft single hairy yarns. 


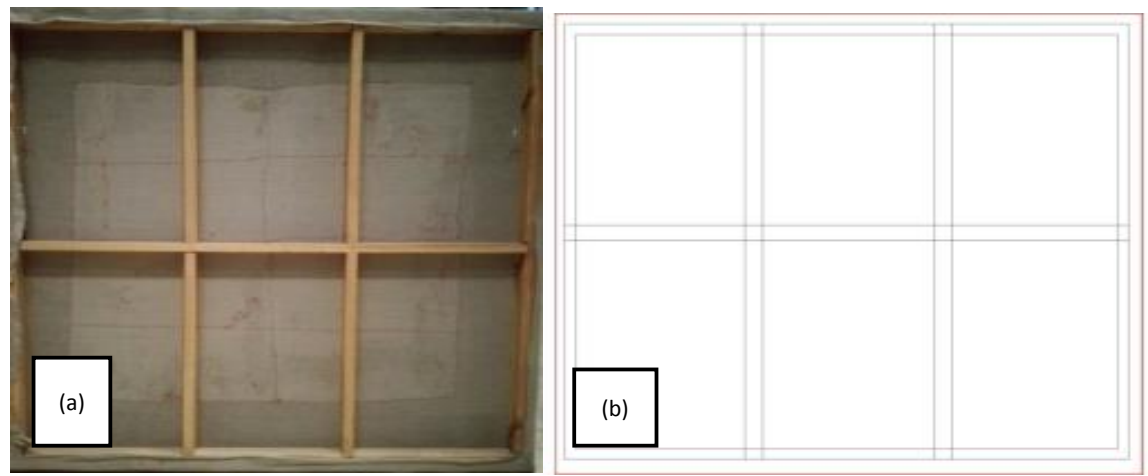

Figure 3. Background of the archaeological textile and the wooden stand.

The archaeological textile is rectangular and measures $85 \mathrm{~cm} \times 90 \mathrm{~cm}$. It comprises four pieces connected using a medium soft red yarn. It is in two parts. The right part is complete and measures $50 \mathrm{~cm} \times 40 \mathrm{~cm}$. The left part consists of three rectangular pieces. While the first lower piece measures $14 \mathrm{~cm} \times 40 \mathrm{~cm}$, the second measures $42 \mathrm{~cm} \times 40 \mathrm{~cm}$, and the third one measures $29 \mathrm{~cm} \times 40 \mathrm{~cm}$.

\subsection{Deterioration Manifestations in the Artifact}

The artifact has some deterioration manifestations, including lint in some parts and fading of the background color because of the inappropriate folding and storing. Consequently, the textile appeared as four attached pieces. A soft layer of dust and dark deposited aerosols covers the artifact, causing severe darkness of the metal threads (see Figure 4). There were clear color changes in the background that appeared because of losing parts of the layers.

There were some hard calcifications on and between the metal threads and inside the textile structure. The textile was harder and less flexible because of the deposited pollutants, dust, and aerosols, as well as humidity that integrated the granules and created hard micro-layers on the metal threads, between the textile structure, and on the background. Because of the high relative humidity and lack of good ventilation tools, some dyes, especially red, caused pale red spots on the weak green background. Furthermore, humidity dissolved some aerosols and dust from the polluted environment surrounding the Museum.

Various vehicles move directly beside the Museum and cause the deposition of hard compounds and aerosols and some of them are saturated with $\mathrm{CO}_{2}$ and $\mathrm{SO}_{2}$ oxidizing into $\mathrm{SO}_{3}$. At available humidity, it turns into $\mathrm{H}_{2} \mathrm{SO}_{4}$.

$$
\mathrm{SO}_{3}+\mathrm{H}_{2} \mathrm{O} \rightarrow \mathrm{H}_{2} \mathrm{SO}_{4}
$$

In addition to its erosion power that causes textile combustion, especially in the background of the artifact, $\mathrm{H}_{2} \mathrm{SO}_{4}$ decreases the textile flexibility because of the interaction of $\mathrm{SO}_{3}$ with internal humidity. Consequently, the water content that is appropriate for maintaining flexibility. When $\mathrm{SO}_{3}$ interacts with some internal textile humidity, the textile has relative dryness and some parts break down (are shown in Figure 5), especially when handling or treating the textile. 


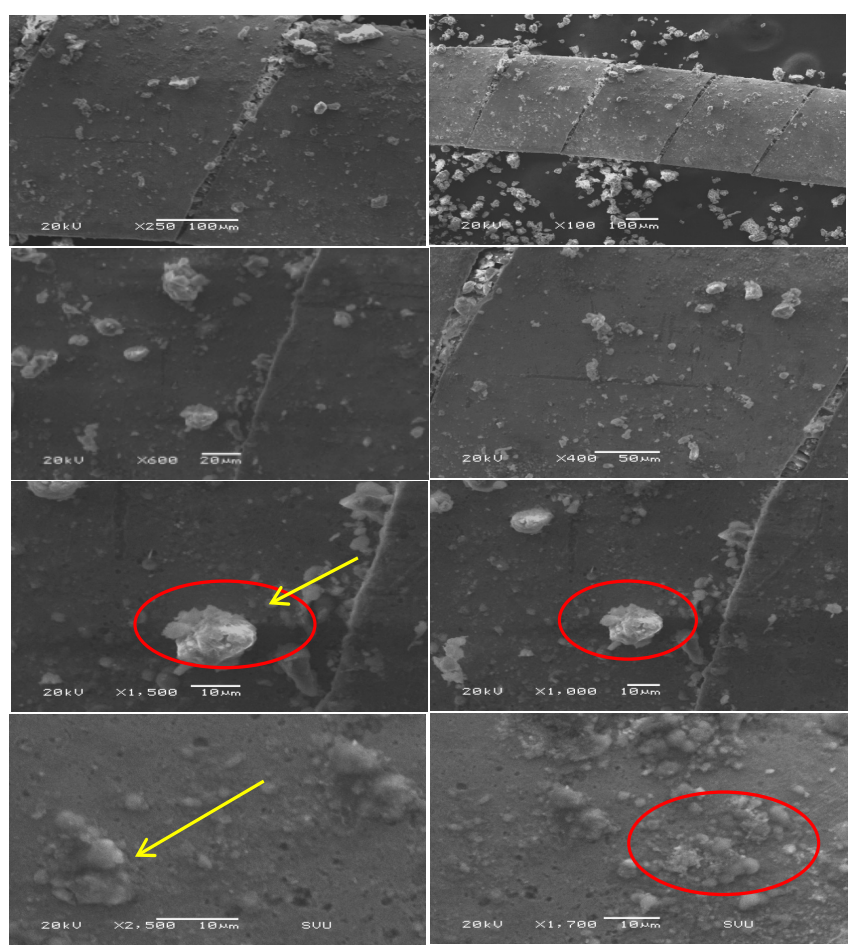

Figure 4. SEM shows corrosion products and dirt calcifications on the metal threads of the archaeological textile before laser cleaning.

Thus, it should be carefully handled. Furthermore, there are heavy dust accumulations, especially in the parts with composite decorations and some parts with lint. There are dirt accumulations in the parts with modified bird wings, stems, and floral motifs. Soot and aerosols are mainly in the shaped parts because they are the first areas they affect.

There are lost areas mainly in the lower right part. Large parts of the artifact are corroded and dry. Therefore, lining appears below the metal texture implemented in the Sirma technique. Reviewing and observing the surrounding areas reveals the deterioration of the metal threads because of loss or having weak yarns in the texture structure. The frame of the textile contains large parts prone to soot, affecting the color. In other words, there are color changes as a result of various soot deposits.

The external parts of the textile have severe lint that should be handled. In the upper right and left areas, some small parts are lost. The external or middle parts are dominated by small and large lesions that should be fixed with proper stitches in order not to affect the other parts and increase deterioration and lint of the metal threads (see Figure 6). Furthermore, the metal threads are non-sparking because of various pollutant deposits that interact with external or internal humidity chemically and result in color changes or corrosion of the metal layers of the metal threads (are shown in Figure 7). As a result of the occurring physical and chemical changes, deterioration rates increase, especially when having acid oxides, including $\mathrm{CO}_{2}, \mathrm{SO}_{2}, \mathrm{SO}_{3}, \mathrm{NO}_{2}$, and $\mathrm{N}_{2} \mathrm{O}_{3}$. 


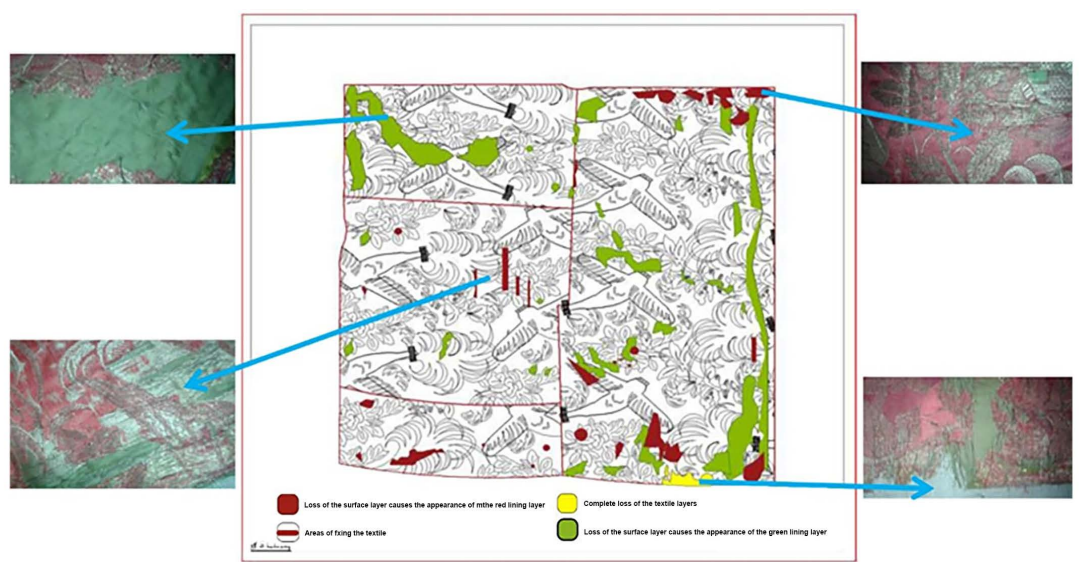

Figure 5. Stereo Microscope shows cuttings of the fibers in the metal threads.

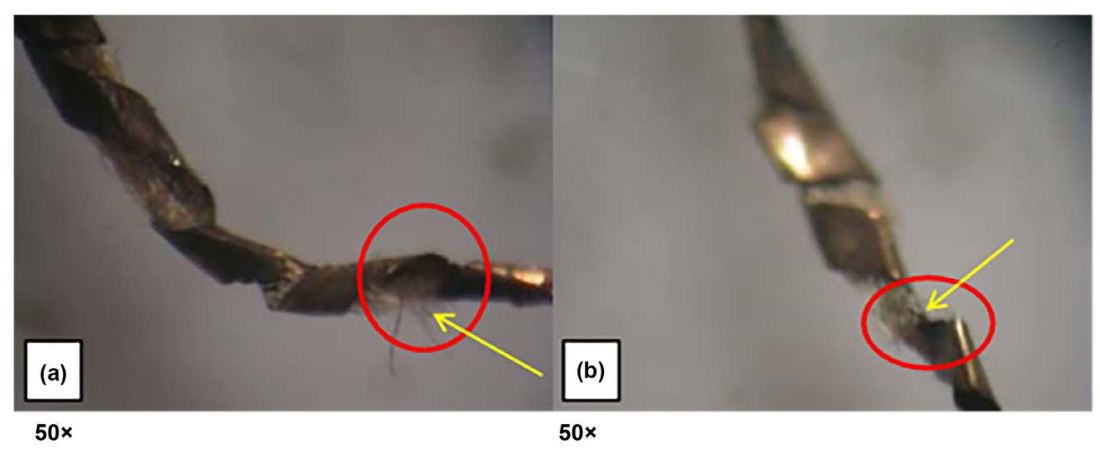

Figure 6. Lost parts in the archaeological textile.
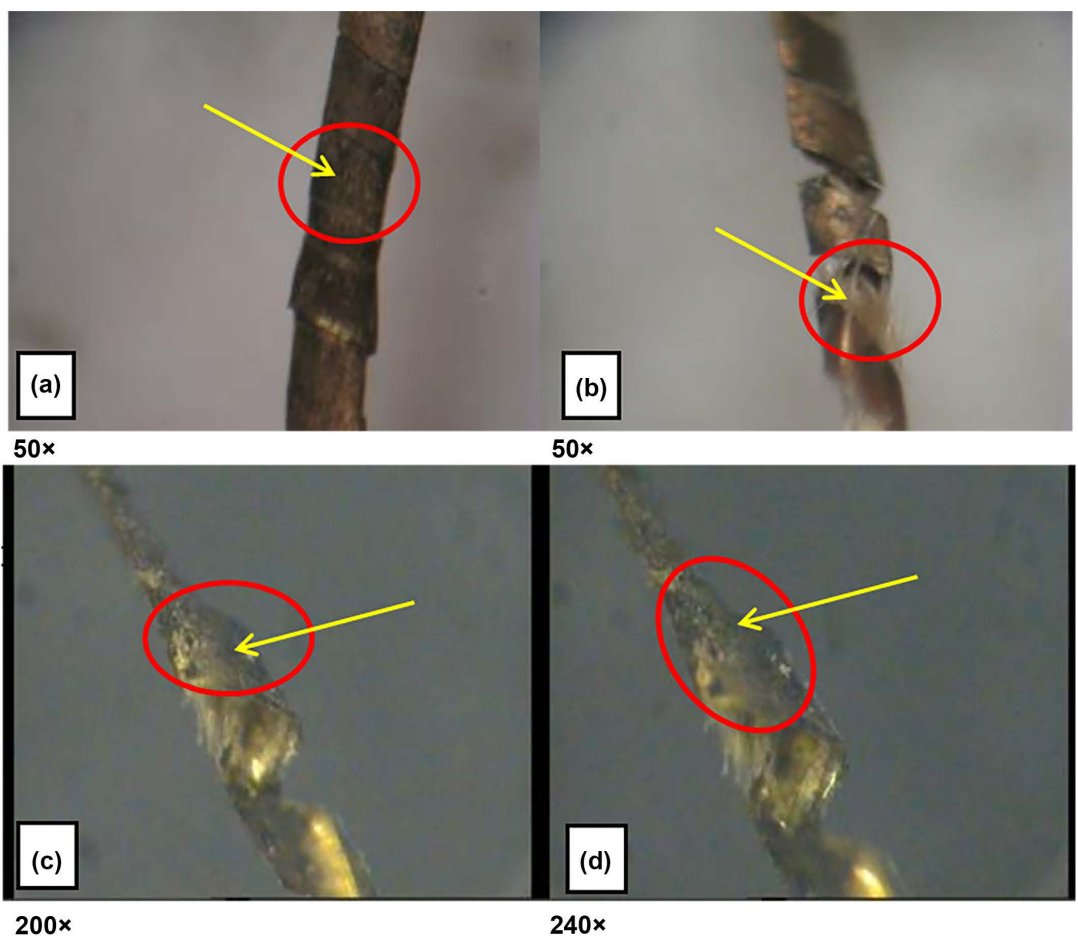

Figure 7. Stereo microscope illustrates the metal threads, as well as layers and effect of corrosion on the fibers before laser cleaning. 
The red layer above the green background containing the artistic aspects of the metal threads appeared contrasting in colors. It was dominated by the dark color because of the deposition of dust and aerosols causing color changes. Deterioration increased because of being a two-layer textile embroidered with metal threads implemented in the Sirma technique on a background of red silk. The decorations were mainly a modified bird or butterfly with various floral motifs. The stand dried, and its color was dark significantly because of dirt and aerosol depositions. It was handled with mechanical and laser cleaning.

\subsection{Laser Techniques and Applications}

Cleaning the composite textile objects is very problematic and requires safe and accurate methods (Elnaggar et al., 2015). The cleaning techniques may be harmful to the metal and textile. Thus, the metal threads are often not cleaned (Hacke, Carr, \& Howell, 2003). Many mechanical and chemical treatments were utilized to clean metal threads on the archaeological textile. However, it is highly recommended to avoid mechanical cleaning methods for metal embroidery threads because of their devastating results that they may remove the noble patina and the coating layer on the cleaned surface. Instead, various materials and methods could be used. Most of the chemical treatments commonly used for cleaningmetal threads are incompatible with the metals and the organic fiber's core, and it is almost impossible for the cleaning solution to avoid contact with the fibers (Abdel-Kareem \& Harith, 2008). Therefore, chemical and mechanical cleaning methods are rarely applied in the case of the coated organic materials (Járó, 2009). The deterioration of metal threads in textile is a complicated problem that cannot be solved by the classical conservation methods. For example, the immersion taking place in chemical or electrolytic corrosion cleaning techniques may damage the fibers and dissolve any dye, while mechanical cleaning may remove the painting.

On the contrary, modern technology application has proved more effective than the traditional methods in the conservation of cultural heritage. Laser is one of the most significant techniques in cleaning, but it is still being examined because of the complexity of rays and the different materials of the textile with metal threads (Radojkouić, Ristic, Zrilić, \& Suzana, 2015).

\section{Materials and Methods}

At this study used some methods Mechanical cleaning, Laser cleaning (see Figure 8), Stereo Microscope (SM) shows fixation with sewing and Scanning Electron Microscopy (SEM) ${ }^{1}$ JEOL JSM-5500 LV Scanning Electron Microscope (JEOL, Japan), Central Lab, South Valley University to study an Archaeological Textile Embroidered with Metal Threads at the Museum of the Faculty of Applied Arts, Helwan University.

${ }^{1}$ Central Laboratory, South Valley University in Qena. 


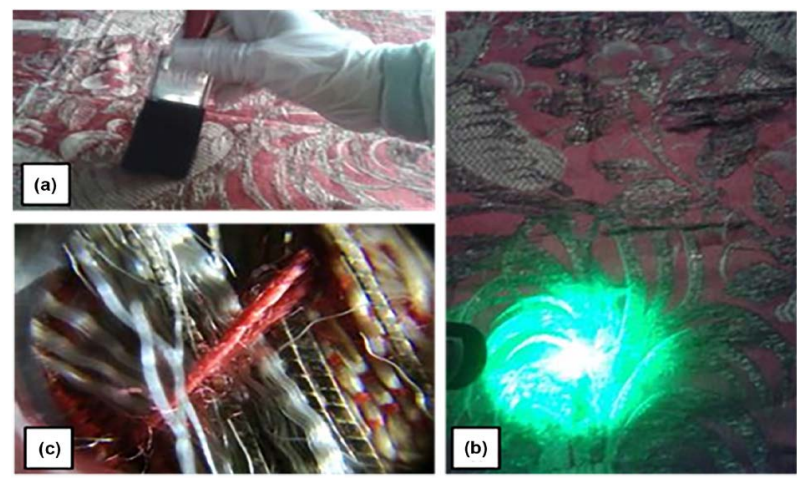

Figure 8. Treatment stages of the archaeological textile.

\subsection{XRF Analysis}

Identifying the chemical composition of all samples was carried out by the X-Ray Fluorescence Analysis (XRF), JEOL JSX Element Analyzer with Energy Dispersive X-Ray Fluorescence system (EDXRF). It helped analyze and identify the components of corrosion.

\subsection{XRD Analysis}

XRD Unit, Assiut University, Model PW 1710 control unit Philips, Anode Material $\mathrm{Cu}, 40 \mathrm{kV}, 30 \mathrm{~mA}, 2$ Cita from 4 to 60 was employed for analyzing the samples and identifying their components. It was applied to a two-layer textile embroidered with metal threads and beige metal decorations on a background of red silk. The simple mechanical cleaning using different brushes was adopted. The stand and the textile were cleaned mechanically in an area of good ventilation in order to make the textile fibers acquire humidity.

The content of relative humidity was increased indirectly through evaporating the surrounding area for many days using a spray far from the textile and the cloth stand. As a result, the textile fibers are wet appropriately to facilitate physical and laser cleaning.

Q-switched Nd:YAG lasers device was used to provide very short pulses of high energy and TEA $\mathrm{CO}_{2}$ laser that was employed successfully to remove the painting (Koh \& Sárady, 2003). In the case of $1046 \mathrm{~nm}$ wavelength, the metal surface changes and various colors, including orange, red, yellow, and blue, appear. The thermal contributions or effects when using $355 \mathrm{~nm}$ ultraviolet rays that are very small do not change the color surface (Ristic et al., 2014). Consequently, deteriorations were removed successfully from the silver surface in wavelengths of $532 \mathrm{~nm}$ and $266 \mathrm{~nm}$. However, $1064 \mathrm{~nm}$ wavelength was inappropriate because they might cause metal melting, as well as cutting and burning the fibers (Koh, Lee, \& Yu, 2003).

Laser cleaning is always related to one of the two types of damage to the surface of the metal. At high energy, deterioration takes place in the form of surface melting. At low energy, the original oxide layer turns into adhered drops of melted metal (Koh, 2005). 
The wavelengths of $193 \mathrm{~nm}$ and $355 \mathrm{~nm}$ achieve better results, but with side effects of fading caused by $355 \mathrm{~nm}$. Recently, laser applications have been developed to make choices of focusing ultrashort rays used successfully to prevent the mechanical and thermal side effects (Elnaggar et al., 2015).

Green laser $^{2}$ (Q-Switched Nd:YAG Lasers) of $352 \mathrm{~nm}$ wavelength was used (Koh \& Sárady, 2003). The archaeological textile was treated using agreen laser for 10 minutes that resulted in good and appropriate results for both the metal threads and silk. It did not cause severe heating like the other types of laser employed in the experimental study, such as (Infrared laser of 1 - $64 \mathrm{~nm}$ wavelength, Ultraviolet laser of 355 - $266 \mathrm{~nm}$ wavelength) in terms of affecting the textile fibers.

\section{Results}

Laser cleaning achieved good results in cleaning corrosion products, including $\mathrm{Cl}, \mathrm{Al}, \mathrm{Ca}$, and $\mathrm{Fe}$ without affecting the metal threads or background see (Figure 9, Figure 10). They were revealed by SEM-EDX, XRF, and XRD analyses.

\section{Discussion}

Results of EDX analysis shows the difference in the archaeological sample before and after laser cleaning, as well as the effect of laser cleaning on $\mathrm{Cl}, \mathrm{Al}$, and $\mathrm{Ca}$. Before cleaning, $\mathrm{Cu}, \mathrm{O}, \mathrm{Cl}, \mathrm{Al}, \mathrm{Ca}, \mathrm{Fe}$ rated (72.98), (19.47), (1.23), (0.35), (0.35), and (0.19), respectively. After laser cleaning, $\mathrm{Cu}$ increased to (79.24) and $\mathrm{O}$ increased to (20.22). $\mathrm{Cl}$ and $\mathrm{Fe}$ did not appear. $\mathrm{Al}$ and $\mathrm{Ca}$ decreased to (0.24) and (0.11), respectively. These results suggest the effectiveness of laser in cleaning the archaeological textile (see Table 2, Figure 11, Figure 12 and Figure 13).

Results of XRF analysis of the first sample of archaeological textile illustrate a high percentage of $\mathrm{CuO}(70.831 \%)$. There are also small amounts of $\mathrm{CaO}(1.062 \%)$ and $\mathrm{Ag}_{2} \mathrm{O}$ (28.107\%). The second sample of the treated textile shows a high amount of $\mathrm{CuO}(68.557 \%)$ and small amounts of $\mathrm{CaO}(0.897 \%)$ and $\mathrm{Ag}_{2} \mathrm{O}(30.546 \%)$ (see Figure 14, Figure 15).

Results of XRD analysis of the first sample of archaeological textile that is not deteriorated illustrates $\mathrm{Cu}$ as a major compound and $\mathrm{Ag}$ as a minor one. The second sample of the textile cleaned by laser shows $\mathrm{Cu}$ as a major compound and $\mathrm{Ag}$ as a minor one. Other resulting oxides appear, highlighting the effectiveness of laser in cleaning the archaeological textile (see Figure 16, Figure 17).

\section{Sewing Support}

After laser cleaning, the lost parts, lint, and external edges were fixed using silk yarns with colors close to those of the textile fibers (dark red-dark green-light beige-olive green) using herring bone stitch, Z-Whip stitch, Laid-couching and slip whip stitch, as well as edges and hole whip stitches (as shown in Figure 18, Figure 19, Figure 20). Consequently, the textile is ready for sorting and exhibiting (are shown in Figure 21).

\footnotetext{
${ }^{2}$ Laser Laboratory, Physics Department, Faculty of Science in Qena, South Valley University.
} 


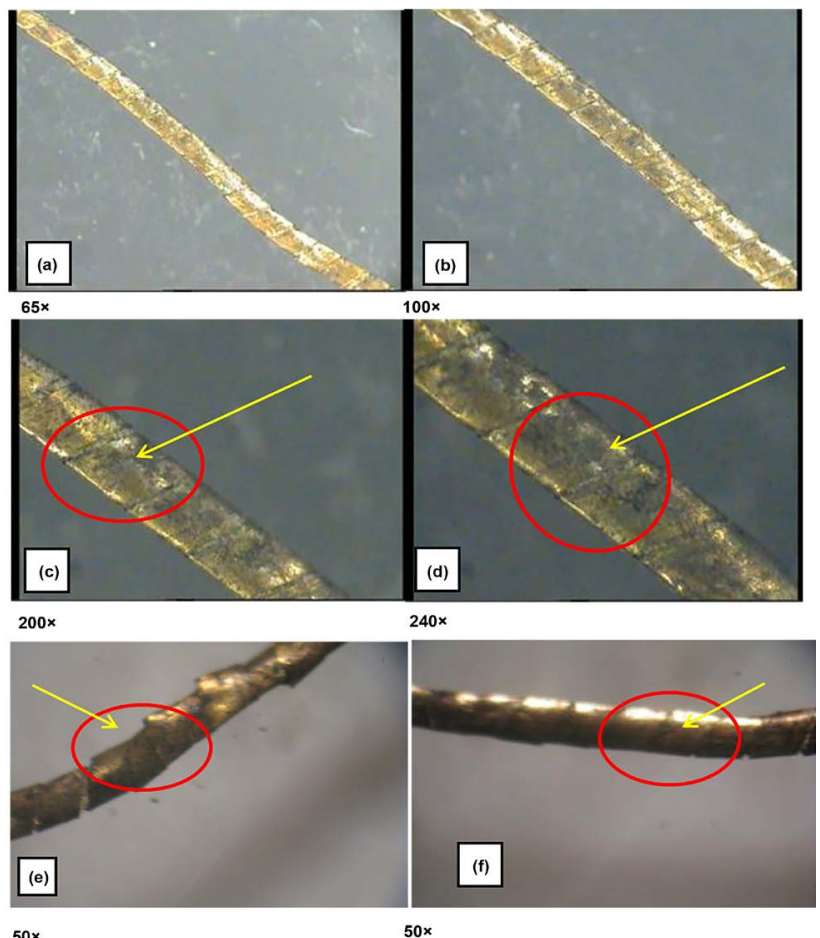

$50 \times$

Figure 9. Stereo Microscope illustrates the metal threads, as well as layers and effect of corrosion on the fibers after laser cleaning.

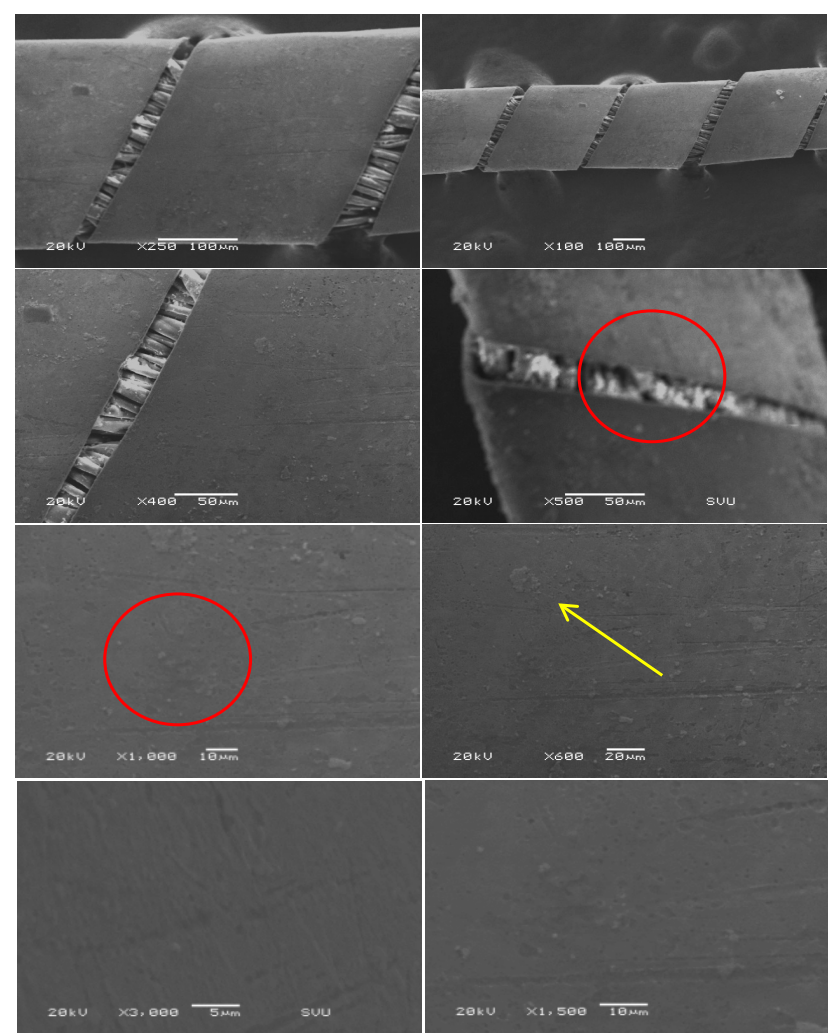

Figure 10. SEM illustrates the removal of corrosion products and dirt calcifications from the metal threads of the archaeological textile after laser cleaning. 


\subsection{EDX Analysis of the Archaeological Textile}

Table 2. The difference of the archaeological textile before and after laser cleaning and effect on $\mathrm{Cl}, \mathrm{Al}, \mathrm{Ca}$, and $\mathrm{Fe}$ after laser cleaning.

\begin{tabular}{cccc}
\hline Samples & Elements & Before Leaser Cleaning & After Leaser Cleaning \\
\hline & $\mathrm{Cu}$ & 72.98 & 79.24 \\
$\mathrm{O}$ & 19.47 & 20.22 \\
$\mathrm{Au}$ & 3.30 & 0.00 \\
$\mathrm{Ag}$ & 2.14 & 0.19 \\
& $\mathrm{Ag}$ & 1.23 & 0.00 \\
& $\mathrm{Cl}$ & 0.35 & 0.24 \\
$\mathrm{Al}$ & 0.35 & 0.11 \\
& $\mathrm{Ca}$ & 0.19 & 0.00 \\
\hline
\end{tabular}

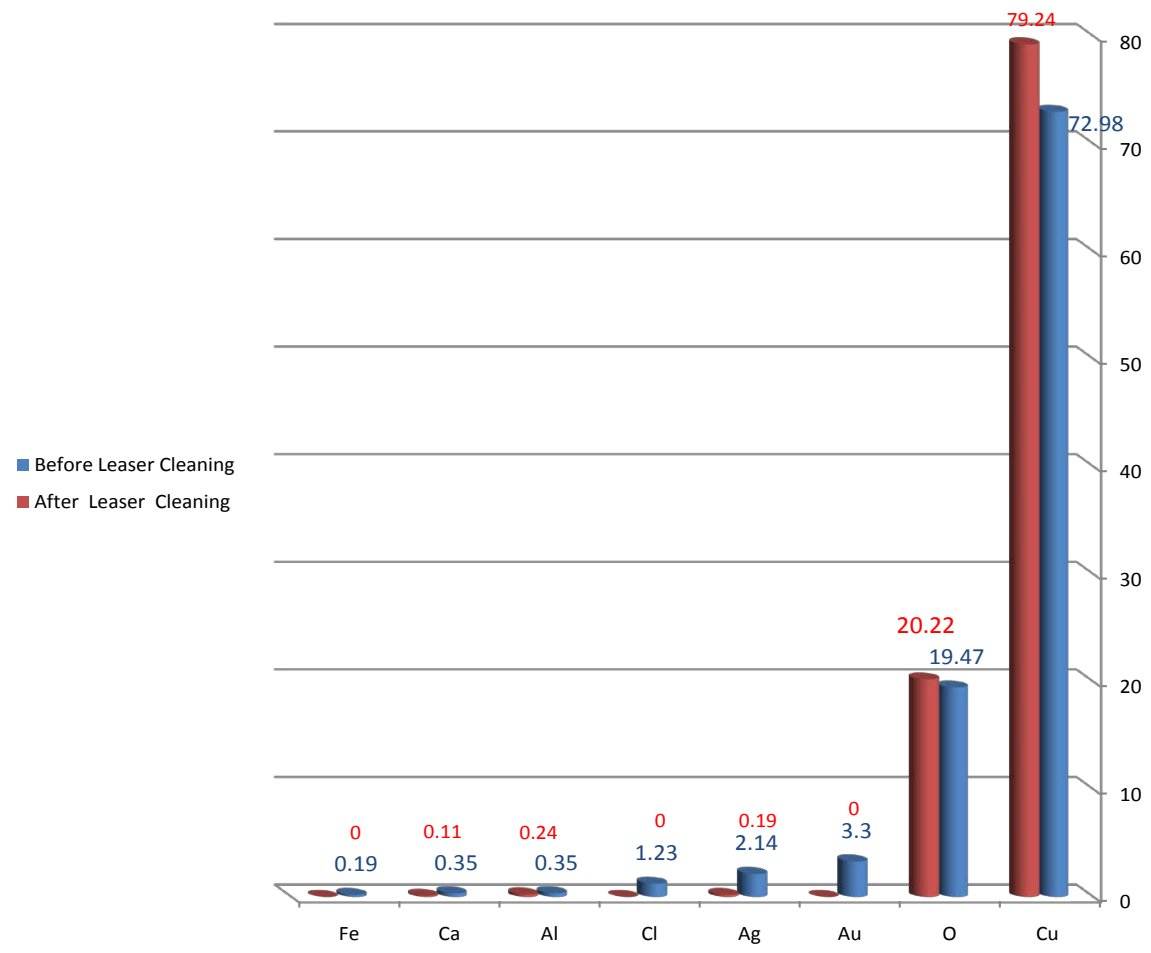

Figure 11. A difference in the archaeological sample before and after laser cleaning.

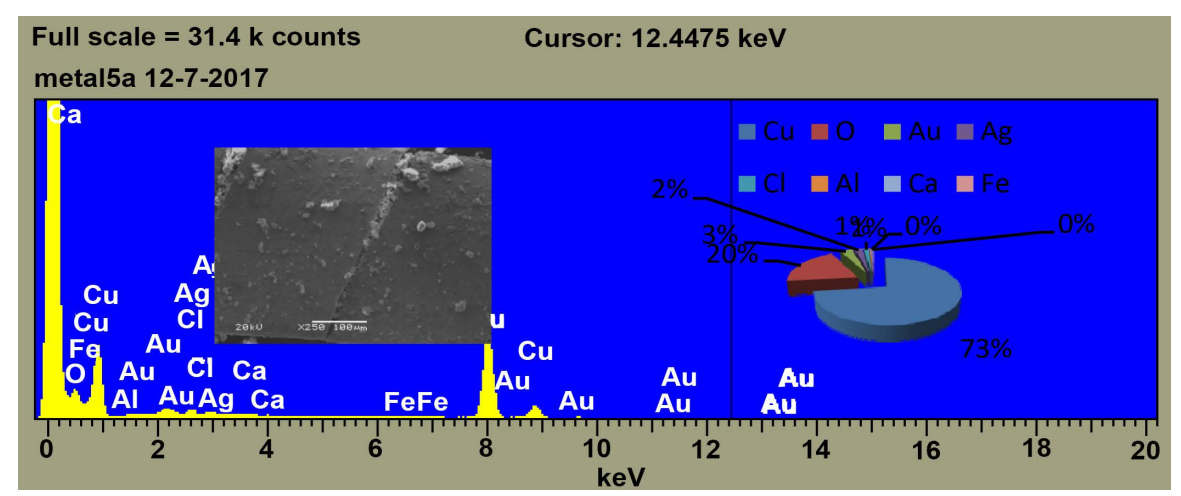

Figure 12. EDX Analysis of the archaeological metal thread before laser cleaning. 


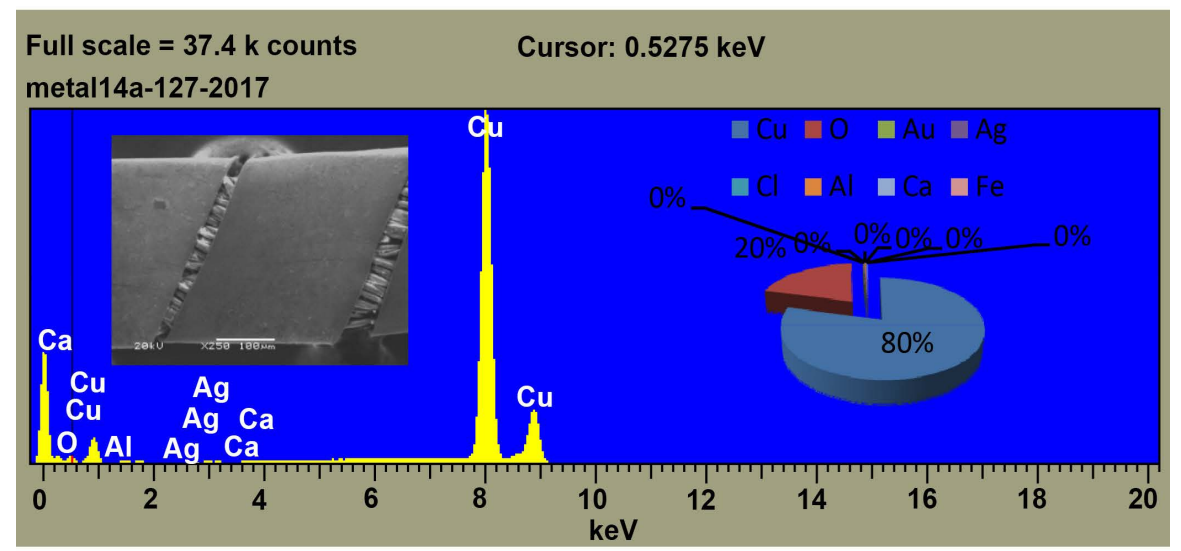

Figure 13. EDX Analysis of the archaeological metal thread sample after laser cleaning.

\subsection{XRF Analysis of the Archaeological Textile ${ }^{3}$ Reveals Some Pollutants and Deteriorating 0xides on the Metal Threads}

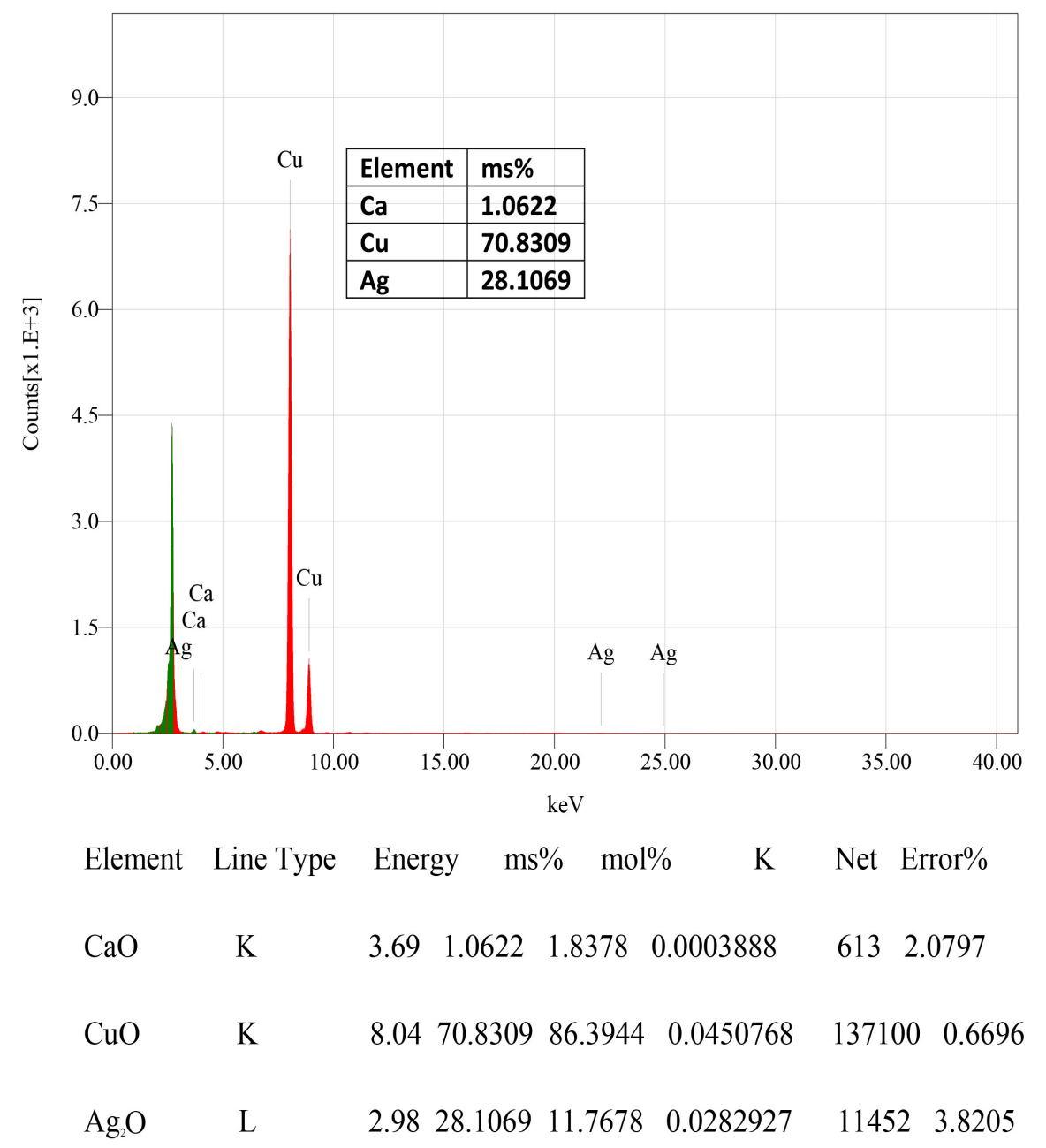

Figure 14. XRF Analysis of the archaeological metal thread sample before laser cleaning show some deteriorating oxides and deterioration residues.

${ }^{3}$ Central Laboratory, South Valley University in Qena. 


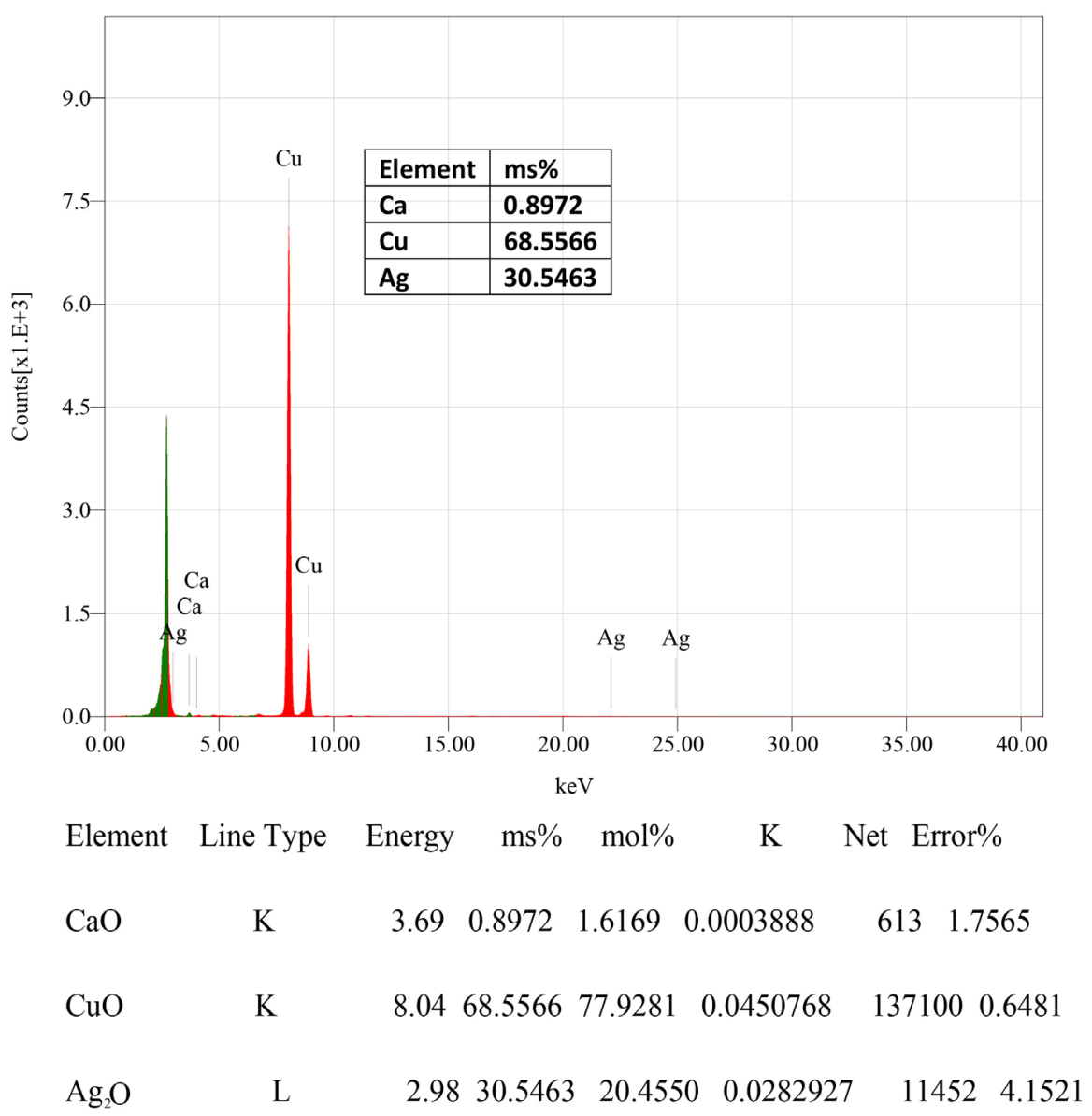

Figure 15. XRF Analysis of the archaeological metal thread sample after laser cleaning showing the effectiveness of laser cleaning.

\subsection{XRD Analysis of the Archaeological Textile ${ }^{4}$ Illustrates $\mathrm{Cu}, \mathrm{Ag}$, and $\mathrm{CuO}$ as Corrosion Products}

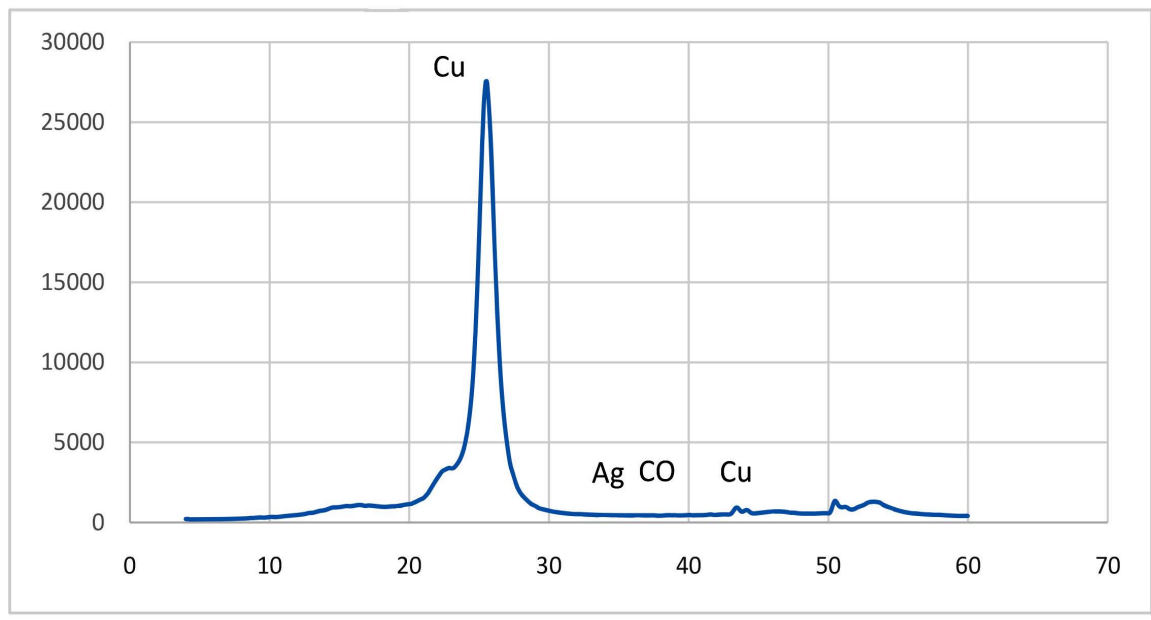

Figure 16. XRD Analysis of the archaeological metal thread sample before laser cleaning illustrates $\mathrm{Cu}, \mathrm{Ag}$, and $\mathrm{CuO}$ as corrosion products. Before treatment: $\mathrm{Cu}=$ copper, $\mathrm{Co}=$ cuprite $(\mathrm{CuO}) ; \mathrm{Ag}=$ Silver.

${ }^{4}$ XRD Laboratory, Physics Department, Faculty of Science in Qena, South Valley University. 


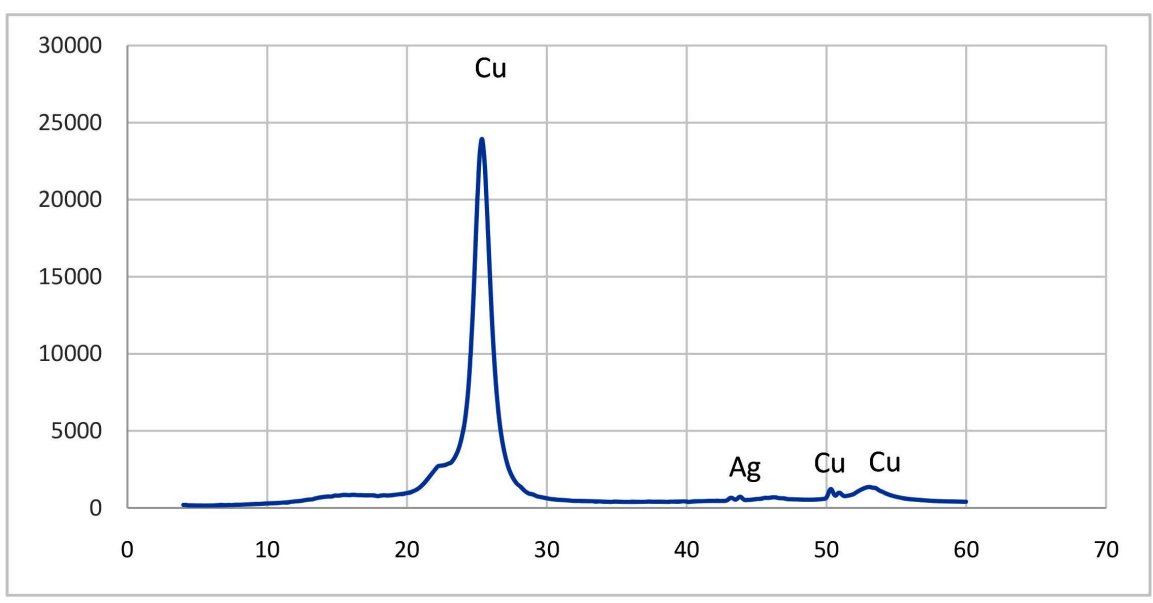

Figure 17. XRD Analysis of the archaeological metal thread sample after laser cleaning illustrates $\mathrm{Cu}$ and $\mathrm{Ag}$ and the effectiveness of laser cleaning in removing corrosion products. After treatment: $\mathrm{Cu}=$ copper; $\mathrm{Ag}=$ Silver.

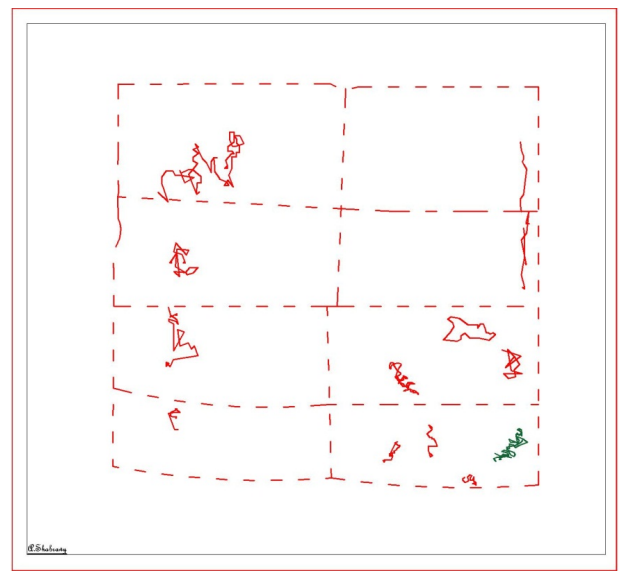

Figure 18. Stitches used in the conservation of the archaeological textile.

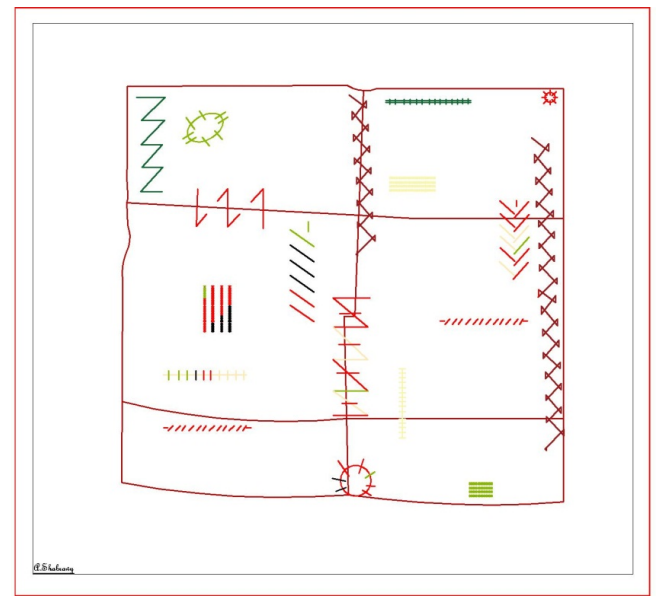

Figure 19. Stitches used in fixing the external edges and deteriorated internal parts of the archaeological textile. 


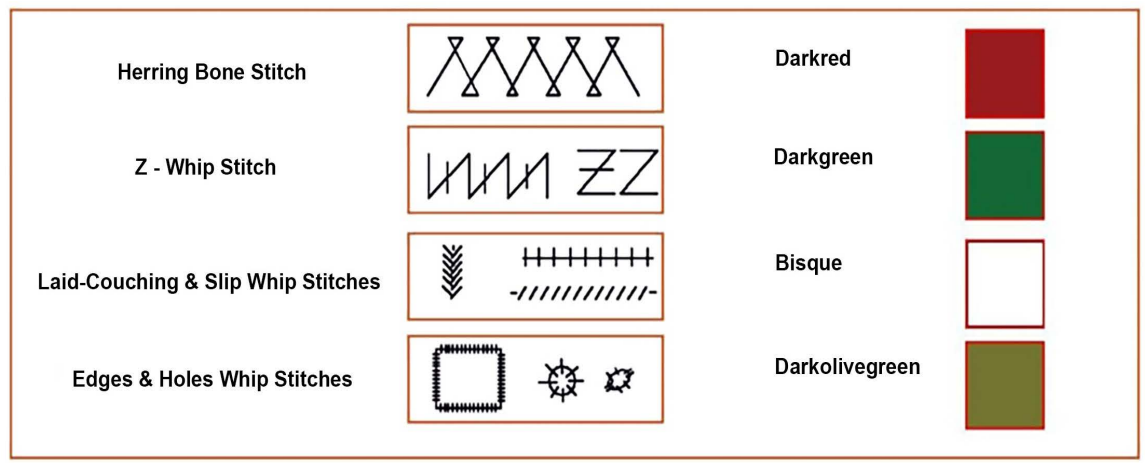

Figure 20. Types of stitches used in fixing the archaeological textile (Conservation Stitching Guide, Stitches Used in Textile Conservation, 1986).

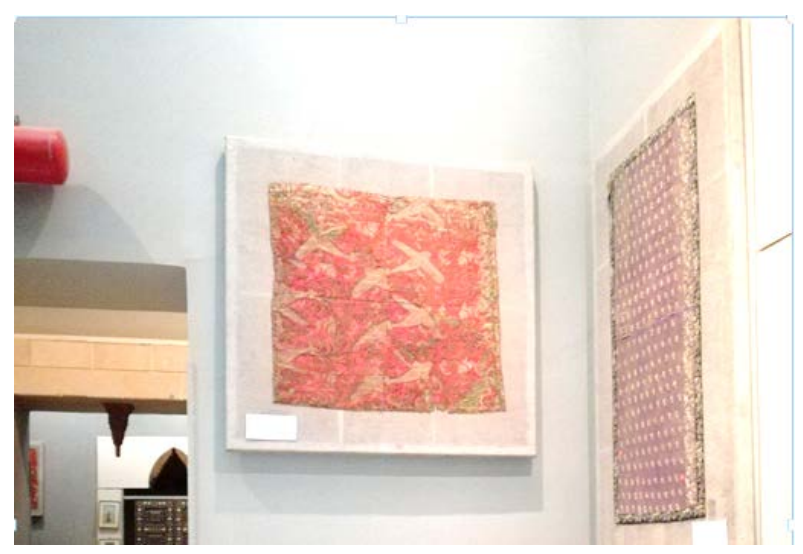

Figure 21. Textile after restoration and keeping at the Museum of the Faculty of Applied Arts, Helwan University (No. 121/5).

\section{Conflicts of Interest}

The authors declare no conflicts of interest regarding the publication of this paper.

\section{References}

Abdel-Kareem, O., \& Al-Saad, Z. (2007). Conservation Strategy of Metal Embroidery Threads in Textile Objects in Museum of Jordanian Heritage. Proceedings the International Conference on Conservation Strategies for Saving Indoor Metallic Collection with a Satellite Meeting on Legal Issues in the Conservation of Cultural Heritage, Cairo, 25 February-1 March 2007, 23-30.

Abdel-Kareem, O., \& Harith, M. (2008). Evaluating the Use of Laser Radiation in Cleaning of Copper Embroidery Threads on Archaeological Egyptian Textiles. Applied Surface Science, 254, 5854-5860. https://doi.org/10.1016/j.apsusc.2008.03.144

Conservation Stitching Guide (1986). Stitches Used in Textile Conservation (pp. 1-3). The staff of the CCI Textile Lab. http://www.museumtextiles.com/

Cybulska, M. (2015). Understanding Textiles from Artist to Spectator. Fibers \& Textiles in Eastern Europe, 3, 133-140. https://doi.org/10.5604/12303666.1152558

Elnaggar, A. et al. (2015). Investigation of Ultrafast Picosecond Laser System for Cleaning of Metal Decorations of 17th C. Gloves of King Charles 1. E-Preservation Science, 12, 14-19. 
Fotakis, C., Anglos, D., Zafiropulos, V., Georgiou, S., \& Tornari, V. (2007). Lasers in the Preservation of Cultural Heritage Principles and Applications. London: Taylor \& Francis Group.

Hacke, A., Carr, C., \& Howell, D. (2003). Investigation into the Nature of Metal Threads in Renaissance Tapestry and the Cleaning of Tarnished Sliver by UV/Ozone (UVO) Treatment. Journal of Materials Science, 38, 3307-3314. https://doi.org/10.1023/A:1025146207048

Járó, M. (1990). Gold Embroidery and Fabrics in Europe: XI-XIV Centuries. Gold Bulletin, 23, 40-57. https://doi.org/10.1007/BF03214711

Járó, M. (2009). Metal Thread Variations and Materials: Simple Methods of Pre-Treatment Identification for Historical Textiles. Conserving Textiles. Studies in Honour of Agnes Timar-Balazsy, ICCROM, 72-75.

Karatzani, A. (2012). Metal Threads: The Historical Development. In I. Tzachili, \& E. Zimi (Eds.), Textiles and Dress in Greece and the Roman East: A Technological and Social Approach (p. 55). Athens: Pragmata Publications.

Koh, Y. (2005). Cleaning Oxides from Copper Artifacts Using a Frequency-Doubled Nd:YAG Laser. Ph.D. Dissertation, Luleå, Sweden: Luleå University of Technology.

Koh, Y., \& Sárady, I. (2003). Cleaning of Corroded Iron Artifacts Using Pulsed TEA $\mathrm{CO}_{2}-$ and Nd:YAG-Lasers. Journal of Cultural Heritage, 4, 129-133. https://doi.org/10.1016/S1296-2074(02)01140-8

Koh, Y., Lee, J., \& Yu, J. (2003). Experimental Study on the Effect of Wavelength in the Laser Cleaning of Silver Threads. Journal of Cultural Heritage, 4, 157-161. https://doi.org/10.1016/S1296-2074(02)01192-5

Radojkouić, B., Ristic, S., Zrilić, M., \& Suzana, P. (2015). Determination of Nd:YAG Laser Parameters for Metal Threads Cleaning in Textile Artefacts. Tehnika-Novimaterijali, 24, 209-215. https://doi.org/10.5937/tehnika1502209R

Ristic, S., et al. (2014) Laser Cleaning of Textile Artifacts with Metal Threads: Process Parameter Optimization. Scientific Technical Review, 64, 50.

Timar-Balazsy, A., \& Estop, D. (1998). Chemical Principles of Textile Conservation (1st ed., p. 128). Oxford: Butterworth-Heineman. 